\title{
How consumers' assessments of the difficulty of manufacturing a product influence quality perceptions
}

\author{
Allison R. Johnson • Valerie S. Folkes
}

Published online: 22 May 2007

(C) Academy of Marketing Science 2007

\begin{abstract}
This research shows that the perceived difficulty of manufacturing a product influences consumers' perceptions of the firm's other products. In three experiments (with 152 participants in Study 1, 86 in Study 2, and 91 in Study 3), participants received information about the quality of a firm's product and then inferred the quality of another product from the firm. When participants believed that the initial product was relatively more difficult to manufacture than the second product, they inferred that the second product would be high in quality. However, when participants believed that the initial product was relatively easy to manufacture, they inferred that the second product would be low in quality. These effects occurred when perceived difficulty of manufacture was manipulated (Study 2) and occurred regardless of whether both products had dissimilar product benefits (Study 1) or whether brand names were present (Study 3).
\end{abstract}

Keywords Product quality. Consumer inferences .

Manufacturing ability . Company expertise .

Difficulty of manufacture - Product portfolio .

Brand extensions

Understanding how consumers arrive at perceptions of product quality is essential for marketers because consum-

Allison R. Johnson and Valerie S. Folkes contributed equally to this article.

A. R. Johnson $(\square)$

Queen's School of Business, Queen's University,

Goodes Hall, Kingston, Ontario, Canada, K7L3N6

e-mail: ajohnson@business.queensu.ca

V. S. Folkes

Marshall School of Business, University of Southern California,

Los Angeles, CA, USA, 90089-0443

e-mail: folkes@marshall.usc.edu ers' judgments influence brand equity, product satisfaction, and the financial performance of the company. Given firms' trends toward consolidation, an increasingly important question is: how does information about one product in the firm's portfolio influence consumers' perceptions of other products in the portfolio? Many firms offer products that vary widely in function and manufacture, though they do so with varying degrees of success. For example, the Yamaha Company originally crafted organs. Now the Yamaha name appears on products with far different purposes, such as motorcycles and golf clubs. Deere \& Company initially sold plows, but the brand currently can be seen on simple outdoor grills. These examples suggest that some firms can offer disparate products quite successfully. Yet, there are other examples of firms abandoning forays into distant product extensions. Unilever's first product was bar soap, but the company has added many different products over the years. Some products in its portfolio have not been successful. One of the products Unilever has abandoned is its home pregnancy testing kits. Société BIC began with a simple disposable pen but, for 6 years, put the BIC brand on the Saxo Bic car. Apparently, the Saxo Bic car was not a very successful product.

Although the reasons for the success of products are undoubtedly complex, a contributing factor is customers' receptiveness to brand extensions. People may have beliefs about the likelihood that a company will make a highquality extension product based on their knowledge of the kinds of products the company currently manufactures. Although firms may believe that a reputation for quality products is sufficient to lead customers to generalize from the high quality of one of their products to a brand in another category, this may not always be the case. The benefit of information about one product's high quality on inferences about the quality of another product from the 
firm may depend on customers' perceptions of the relative difficulty of manufacturing those products. Previous research has shown that consumers have beliefs about the difficulty of designing and making products; some products (e.g., popcorn, frozen French fries) are perceived as easy, and others (e.g., watches, wine) are perceived as more difficult (Aaker and Keller 1990). Furthermore, consumers' beliefs about the difficulty of manufacturing an extension influence their attitudes toward that brand extension, though the strength of those effects sometimes varies across studies (Bottomley and Holden 2001).

The difficulty of manufacturing an existing product may influence consumers' inferences about the firm's ability to make another high-quality product. Many product portfolio studies have referred to consumers' attributions about a firm's expertise or competencies (e.g., Aaker and Keller 1990; Boush and Loken 1991; Brown and Dacin 1997). However, none has elaborated on how such inferences influence product quality perceptions when the relative difficulty of manufacturing products varies. Our research investigates the effects of relative difficulty of manufacture in more depth than previous research to shed light on when and why this important construct influences consumers' quality inferences.

We conducted a series of experiments to examine the effects of relative manufacturing difficulty on quality perceptions by systematically varying difficulty of manufacture for (1) the initial product (for which difficulty of manufacture has not been measured in prior research) and (2) the second product (for which difficulty of manufacture has been measured but not manipulated in prior research). These experiments show that consumers believe that firms making a high-quality product can make another highquality product that is perceived as easier to manufacture (e.g., Heineken can make high-quality popcorn), but they are skeptical of the quality of another product that they perceive as more difficult to manufacture (e.g., Orville Redenbacher's may not be able to make high-quality beer). These effects of the relative difficulty of the two products have not been identified in previous research and may explain inconsistencies in the literature.

\section{Quality inferences when products vary in difficulty}

Consumers often lack direct information about a product's quality and instead must infer quality from other cues or signals (e.g., Hansen and Zinkhan 1984; Kirmani and Rao 2000). There are several obstacles to consumers' using direct information about a firm's ability to make a highquality product. Although information about a firm's manufacturing capabilities might be gleaned from technical reports, annual reports, and business journals, most con- sumers lack access to those sources and the motivation to invest effort into deciphering and synthesizing that information. Some firms do provide information about their manufacturing capabilities in their marketing promotions. For example, 3M (http://solutions.3M.com/en) emphasizes the company's superior manufacturing ability in its marketing communications. However, a firm's self-aggrandizing messages often suffer from a lack of credibility; the products must speak for themselves.

When making inferences about quality, consumers are more likely to use information that is accessible, concrete, and easy to process (Hansen and Zinkhan 1984). A type of information that fulfills these requirements is the kinds of products a firm makes. Indeed, several studies have suggested that consumers use the type and quality of one of a firm's products to infer the quality of its other products (e.g., Aaker and Keller 1990; Boush and Loken 1991). More specifically, both the similarity between products in a firm's portfolio and the extension product's manufacturing difficulty have been shown to influence attitudes toward brand extensions.

Effects of the difficulty of manufacturing a product

The current research focuses on the relative difficulty of manufacture as a potential cue for the firm's more general manufacturing ability. Prior research has shown that even consumers with no special knowledge about manufacturing have beliefs about the difficulty of manufacturing a product (Aaker and Keller 1990). Although brand extension research has indicated that an extension's perceived difficulty may influence attitudes toward that extension (Aaker and Keller 1990), the evidence is mixed. The perceived difficulty of manufacturing the extension is associated with positive evaluations in some studies and with negative evaluations in other studies, and sometimes it has no significant relationship with extension evaluations (Bottomley and Holden 2001).

Here, we test the notion that the perceived difficulty of manufacturing one product in the firm's portfolio influences beliefs about the quality of another product, depending on the relative difficulty of manufacturing the two products (i.e., not only the difficulty of the extension). Consumers are likely to expect that a company that makes what is perceived to be an easy product has less manufacturing ability than a company that makes what is perceived to be a difficult product. Having made an inference about the firm's competence from the product it manufactures, a consumer then can generalize about the quality of other products that share the same family brand or corporate brand logo. It is fairly straightforward for a consumer to infer that a firm that successfully makes an easy product has the ability to successfully make other relatively easy-to- 
manufacture products. However, success at an easy task does not predict success at more difficult tasks (e.g., Meyer et al. 1976; Weiner and Kukla 1970). Thus, consumers are likely to be skeptical about a firm's ability to make a highquality product that is more difficult to manufacture than its original product. In contrast, success at a difficult task predicts success at other difficult tasks, as well as easy tasks. Therefore, consumers should be more likely to assume that a firm that makes a difficult-to-manufacture product can also make other high-quality products, including those that are easy to manufacture and those that are similarly difficult to manufacture.

The effect of the relative difficulty of manufacturing products has not been tested systematically, but theory in psychology on inferences about ability (Jones et al. 1968) and prior research in marketing on brand extensions imply that our hypotheses might be supported. Brand extension research has ignored the relative manufacturing difficulty of the parent product (e.g., Aaker and Keller 1990). Neglecting the relative difficulty of manufacturing the parent product might give an incomplete picture of the effects of manufacturing difficulty on brand evaluations. For example, a study might find negative attitudes toward difficult extensions if it paired the difficult extensions with parent products that were perceived as easier to manufacture. Another study might find that an extension's difficulty has no effect on attitudes if it included parent and extension product pairs that are similar in manufacturing difficulty, even if the level of difficulty varied considerably across extensions. That type of variation in methodology might explain mixed findings for the effects of manufacturing difficulty (see Bottomley and Holden 2001 for a review).

\section{Effects of product benefit similarity}

Product similarity is another cue of a firm's ability to make a high-quality product (e.g., Martin and Stewart 2001). Aaker and Keller (1990) examined the effects of overall perceived similarity between a parent and an extension on attitudes toward the extension. They hypothesized that when products do not "fit," consumers doubt whether the firm's skills in making the original product will transfer to the design and manufacture of a product extension. Thus, similarity should contribute to perceptions of a firm's ability or competence to make an extension product. Similarity between a parent and an extension enhances extension quality perceptions (Aaker and Keller 1990). Product benefit similarity is examined here, which is a facet of general perceived similarity that Aaker and Keller (1990) examined.

Greater expertise should be suggested when the second product that a consumer learns about provides the same benefit as the first product (e.g., both are cleaning products) than when it provides different benefits (e.g., one is a cleaning product, and the other is a food product). Benefit similarity may suggest that the firm has insight into consumers' needs in that domain that can be subsequently applied to the design and creation of another product that serves similar needs. Benefit similarity should be a signal that influences quality inferences, and that effect should be independent of manufacturing difficulty.

\section{Hypotheses}

We propose that knowing that a firm makes a high-quality, difficult-to-manufacture product suggests the firm's competence in making easy-to-manufacture products. In contrast, knowing that a firm makes a high-quality, easy-to-manufacture product creates an impression of the firm's manufacturing ability that is not easily reconciled with subsequent information that the firm makes a difficult-to-manufacture extension product. In addition, although we expect that product benefit similarity influences predictions of quality, the effects of relative manufacturing difficulty should be observed regardless of the benefit similarity between the two products. We hypothesize a main effect for manufacturing difficulty and no interaction with benefit similarity, consistent with the absence of an interaction in Aaker and Keller's (1990) results. Products that are similar in the benefits they provide should lead to more positive quality perceptions than products that are dissimilar. However, a relatively easyto-manufacture extension should be perceived more positively than a relatively difficult-to-manufacture extension, even if both products serve to provide the same benefit.

Hypothesis 1 When the firm's first product is perceived as more difficult to manufacture than the second product, consumers' perceptions of the second product's quality are more positive than when the first product is perceived as easier to manufacture than the second product, regardless of benefit similarity.

When both products are perceived as similar (both easy or both difficult to manufacture), the high quality of the initial product should suggest higher quality for the second product than when the initial product is easier to manufacture than the second product. Making an additional product that is matched in the level of manufacturing difficulty, compared with a product that is relatively more difficult, should be consistent with consumers' initial assessments of the firm's competence.

Hypothesis 2 When the firm's first product is perceived as less difficult to manufacture than the second product, consumers' perceptions of the second product's quality are more negative than when the two products are perceived as similar in difficulty. 
Hypotheses 1 and 2 are based on the assumption that manufacturing difficulty influences quality estimates for the second product because it combines with information about the first product's quality to serve as a signal of the firm's ability. Signaling requires that consumers make inferences (Kirmani and Rao 2000). In comparison, direct information about a firm's manufacturing ability should eliminate the need for consumers to draw inferences about ability from manufacturing difficulty. Thus, the negative quality perceptions of a second product that is relatively more difficult to manufacture than the first product should be eliminated when consumers have a favorable impression of the firm's competence in manufacturing.

Hypothesis 3 Direct information about the firm's high manufacturing ability eliminates the effect of relative manufacturing difficulty. When the first product is easier to manufacture than the second product, consumers' perceptions of the second product's quality are more positive when the consumer knows that the firm has high manufacturing ability than when the consumer has no direct ability information.

In summary, our research examines three hypotheses about the effects of the relative difficulty of manufacturing products on product-quality inferences. Our studies each followed the same general procedure in testing these hypotheses. Respondents received information about the quality of one product and then were asked about the quality of another product from the same firm. The initial study was a pretest to confirm that relative manufacturing difficulty is an important construct that consumers use. The three main experiments measured consumers' ratings of a second product's quality. Study 1 varied relative manufacturing difficulty and measured quality perceptions for the second product to test Hypothesis 1. Study 2 manipulated the products' perceived manufacturing difficulty to test both Hypothesis 1 and Hypothesis 2. Study 3 provided direct information about the firm's manufacturing ability and systematically varied relative manufacturing difficulty to test Hypotheses 1 and 3 in the context of real brand names.

\section{Pretest}

Before we examined the effects of relative difficulty of manufacture in an experimentally systematic way, we undertook a pretest to determine whether it is an important construct that consumers use to make inferences. The pretest examined consumers' thoughts in response to information that products in a firm's portfolio were discrepant in relative manufacturing difficulty. We varied the perceived difficulty of manufacturing the initial product and whether that product was relatively more or less difficult to manufacture than a second product. Consumers' thoughts should reflect their inferences about the firm's ability, with more doubts expressed about its ability when their impressions are based on information that the firm makes an easy product. Introducing a relatively difficult second product should be inconsistent with their initial assessment of the firm's ability. We examined two pairs of products to provide some evidence of the generality of the phenomenon.

\section{Method}

One hundred fifty-two students (59\% were female and $41 \%$ were male, with a mean age of 20.8 years) volunteered to participate in exchange for partial course credit. A $2 \times 2$ fullfactorial between-subjects design was used, varying the ease of manufacturing the initial product (the first impression was based on the relatively difficult-to-manufacture product vs. the relatively easy-to-manufacture product) and varying the similarity of the benefits offered by the product pair (both products offered similar benefits vs. each product offered different benefits). As in prior research, the pretest manipulated difficulty of manufacturing by varying the type of product (e.g., Aaker and Keller 1990). In contrast to the methods used in prior research, however, the pretest systematically varied the quality information for both products in a given pair. For example, in some conditions, quality information was given about vacuum cleaners, and participants made inferences about vacuum cleaner bags; in other conditions, quality information was given about vacuum cleaner bags, and participants made inferences about vacuum cleaners. Furthermore, all product pairs were discrepant in difficulty of manufacture.

The similar-benefit pair was vacuum cleaners and vacuum cleaner bags, and the dissimilar-benefit pair was vacuum cleaners and juice (all functional products; see Park et al. 1991). Each product pair is discrepant in difficulty of manufacturing, with vacuum cleaners perceived as a more difficult-to-manufacture product than either vacuum bags or juice. Thus, the four conditions were (1) vacuum cleaner information given before information that the company also makes vacuum bags, (2) vacuum bag information given before introducing vacuum cleaners, (3) vacuum cleaner information given before introducing juice, and (4) juice information given before introducing vacuum cleaners.

In all conditions, participants were told that a consumer magazine had ranked the products from many different companies on the basis of their quality and that the product from this particular company was among the top-ranked brands. Juice was ranked on its flavor (i.e., better flavor than the juice from other companies). Vacuum cleaners and vacuum cleaner bags were ranked on their reliability (i.e., less likely to break down). After participants read about the 
quality of the first product, they were asked to rate its quality. This initial rating served as a manipulation check and served an additional purpose because it ensured that participants formed initial beliefs about the company's products, which they must to arrive at the initial quality judgment (Hogarth and Einhorn 1992). Specifically, participants were asked, "What would you expect the quality of the juice (vacuum cleaners, vacuum bags) made by this company to be?" They responded using three 9-point Likert scales, anchored by very bad-very good, very low quality - very high quality, and poor-excellent. Perceptions of quality on a specific attribute (i.e., flavor or reliability) should influence a global or overall measure of quality (Zeithaml 1988). The three items showed high reliability in measuring perceived quality $(\alpha=.95)$, and as intended, the mean rating indicated that respondents believed that the initial product from the company was high quality $(M=8.49)$.

After learning that the firm manufactured the second product, participants wrote down their thoughts about the company on an open-ended item. Two independent raters classified participants' responses on the basis of whether the thoughts were relevant to the company's manufacturing ability and, if they were, which of three categories of ability the response indicated. The first category consisted of perceptions that the company possessed manufacturing ability in a particular product category. The second category captured doubts about the company's ability and perceptions that the company lacked the ability to make both products well. The third category represented responses that indicated high manufacturing ability or positive perceptions of the company's products. There was $99 \%$ agreement between the raters in classifying responses into these categories (intraclass $r=.96, p<.05$ ), indicating high inter-rater reliability.

Finally, participants rated the difficulty of manufacturing the products, from 1 (not at all difficult) to 9 (very difficult). Our measure of the difficulty associated with making the product was based on the single-item measure that Aaker and Keller (1990) used. Participants perceived vacuum cleaners as more difficult to manufacture than juice (vacuums: $M=7.42$; juice: $M=4.25 ; t(82)=11.77, p<.05)$ and as more difficult to manufacture than vacuum bags $(M=4.07$; $t(67)=12.25, p<.05)$.

\section{Results and discussion}

The content analysis of respondents' thoughts supports the rationale underlying the hypotheses. Information about products in the firm's portfolio led respondents to think about the firm's manufacturing ability. The majority of respondents $(92 \%)$ referenced the company's ability. Of respondents who referenced ability, 33\% described beliefs that the company lacked the ability necessary to make both products well. These participants indicated that they had doubts about the quality of the second product (e.g., "I don't believe that making juice means that they would be able to make vacuum cleaners"). Impressions based on a relatively easy-to-manufacture initial product were more likely to lead to doubts about the company's ability than were impressions based on the more difficult product $(21$ vs. $11 \%$, respectively; $\chi^{2}=4.26, \mathrm{df}=1, p<.05$ ). In addition, thoughts related to doubting the company's ability to make both products well were more likely in the dissimilar product conditions than in the similar product conditions ( 29 vs. $4 \%$, respectively; $\chi^{2}=28.17, \mathrm{df}=1, p<.05$ ).

Some respondents ( $12 \%$ of those who referenced ability) described beliefs that the company's ability was more specialized in a particular type of product (e.g., "This is a company that makes vacuums and other related products"). Responses referring to the company as having ability that was specific to one type of product, rather than ability that could be generalized across domains, were significantly more likely in the similar product pair conditions than in the dissimilar product pair conditions (11 vs. $1 \%$, respectively; $\left.\chi^{2}=13.24, \mathrm{df}=1, p<.05\right)$. There was no significant effect of relative difficulty on these types of responses $(6 \%$ in both the easy and the difficult initial product conditions; $\chi^{2}=0.06, \mathrm{df}=1$, n.s.).

In summary, the pretest suggests that consumers assess a firm's ability on the basis of the products it makes. Consumers are likely to doubt the company's ability to make a relatively difficult product when their impressions are based on a relatively easy-to-manufacture product. These results support the rationale underlying Hypotheses 1 and 2. Building on the results of this study, which suggest that relative difficulty of manufacturing affects inferences about the firm, Study 1 tested Hypothesis 1 regarding quality inferences.

\section{Study 1}

Study 1 used the same method and design as the pretest but measured quality perceptions to test Hypothesis 1. We predicted that information about an initial product that is more difficult to manufacture than the second product would enhance quality perceptions more than if the initial product is less difficult than the second. Study 1 examined manufacturing difficulty effects for the same two pairs of products as in the pretest. Again, both pairs of products were discrepant in manufacturing difficulty.

Method

Eighty-six students (54\% were female and $46 \%$ were male, with a mean age of 23.3 years) were recruited on a large 
university campus and were randomly assigned to conditions. The same $2 \times 2$ design was used as in the pretest, varying the similarity of the product benefits (similar vs. dissimilar) and the manufacturing difficulty of the initial product (the first impression was based on the relatively difficult-to-manufacture product vs. based on the relatively easy-to-manufacture product). The second product was always discrepant in difficulty of manufacture from the initial product. Thus, the four conditions were (1) vacuum cleaner information given to make inferences about vacuum bags, (2) vacuum bag information given to make inferences about vacuum cleaners, (3) vacuum cleaner information given to make inferences about juice, and (4) juice information given to make inferences about vacuum cleaners (see Table 1).

Participants indicated their quality perceptions on the same three-item measure used in the pretest. As intended, the mean rating again indicated that respondents believed that the initial product was high in quality $(M=7.59)$. Then, participants rated the quality of the second product, which, after ratings of the initial product had been completed, was described as another product from the same company. Both quality measures evidenced high reliability $(\alpha>.95)$.

Respondents then answered three questions about the similarity of the benefits the products provided, namely, whether the products were similar in what they were used for, whether they satisfied similar needs or goals, and whether they were used in similar situations (Martin and Stewart
2001). These three items were rated on 9-point scales, from 1 (not at all) to 9 (very much) $(\alpha=.94)$. As intended, the dissimilar-benefit pair (juice and vacuum cleaners) were rated as significantly less similar in benefits than the similarbenefit pair (vacuum cleaners and vacuum bags) $(M=1.83$ vs. $M=6.92$, respectively; $F(1,81)=210.95, p<.05)$. Perceived similarity did not significantly differ on the basis of variation in the initial product or the interaction of the two factors $(F(1,81)=0.23$, n.s. $)$. In addition, a principal components factor analysis with an orthogonal varimax rotation shows that the quality items load on separate factors from the similar-benefit items (one factor represented the initial product's quality, one represented the second product's quality, and one represented benefit similarity); no crossloadings between the two types of items were greater than 0.30 . Thus, the measure of similarity in product benefits shows discriminant validity from the measures of the initial product's and the second product's quality.

Participants also rated each product on its difficulty of manufacture using the same measure as in the pretest. Within-subjects comparisons indicate that the expected patterns of perceived difficulty of manufacture emerged. Participants perceived vacuums as significantly more difficult to manufacture than vacuum bags (vacuums: $M=$ 6.43; vacuum bags: $M=2.93$; $t(45)=8.74, p<.05$ ). Participants also considered vacuums a significantly more difficult product to manufacture than juice (vacuums: $M=$ 6.43; juice: $M=2.68 ; t(39)=9.65, p<.05)$. Difficulty ratings

Table 1 Mean perceived quality of the second product in the firm's portfolio and each experiment's manipulations

\begin{tabular}{|c|c|c|c|c|}
\hline \multirow[t]{2}{*}{ Study manipulations } & \multicolumn{2}{|c|}{$\begin{array}{l}\text { Difficulty of product } \\
\text { presented first }\end{array}$} & \multicolumn{2}{|l|}{ Difficulty of second product, relative to: } \\
\hline & $\begin{array}{l}\text { Easy first } \\
\text { product }\end{array}$ & $\begin{array}{l}\text { Difficult } \\
\text { first product }\end{array}$ & Easy first product & Difficult first product \\
\hline \multicolumn{5}{|l|}{ Study 1} \\
\hline Similar-benefit pair & 6.32 & 7.15 & $\begin{array}{l}\text { The second product is more difficult } \\
\text { (Easy bags to difficult vacuums) }^{\mathrm{a}}\end{array}$ & $\begin{array}{l}\text { The second product is easier } \\
\text { (Difficult vacuums to easy bags) }\end{array}$ \\
\hline Dissimilar-benefit pair & 3.93 & 5.93 & $\begin{array}{l}\text { The second product is more difficult } \\
\text { (Easy juice to difficult vacuums) }\end{array}$ & $\begin{array}{l}\text { The second product is easier } \\
\text { (Difficult vacuums to easy juice) }\end{array}$ \\
\hline \multicolumn{5}{|l|}{ Study 2} \\
\hline $\begin{array}{l}\text { Similar difficulty in } \\
\text { manufacturing }\end{array}$ & 6.31 & 5.65 & $\begin{array}{l}\text { Both products are similarly easy } \\
\text { (Easy juice to easy vacuums) }\end{array}$ & $\begin{array}{l}\text { Both products are similarly difficult } \\
\text { (Difficult juice to difficult vacuum) }\end{array}$ \\
\hline $\begin{array}{l}\text { Discrepant difficulty in } \\
\text { manufacturing }\end{array}$ & 4.13 & 7.22 & $\begin{array}{l}\text { The second product is more difficult } \\
\text { (Easy juice to difficult vacuums) }\end{array}$ & $\begin{array}{l}\text { The second product is easier } \\
\text { (Difficult juice to easy vacuum) }\end{array}$ \\
\hline \multicolumn{5}{|l|}{ Study 3} \\
\hline $\begin{array}{l}\text { No manufacturing } \\
\text { ability information }\end{array}$ & 3.95 & 6.01 & $\begin{array}{l}\text { The second product is more difficult } \\
\text { (Easy popcorn to difficult beer) }\end{array}$ & $\begin{array}{l}\text { The second product is easier } \\
\text { (Difficult beer to easy popcorn) }\end{array}$ \\
\hline $\begin{array}{l}\text { High manufacturing } \\
\text { ability information }\end{array}$ & 6.18 & 6.11 & $\begin{array}{l}\text { The second product is more difficult } \\
\text { (Easy popcorn to difficult beer) }\end{array}$ & $\begin{array}{l}\text { The second product is easier } \\
\text { (Difficult beer to easy popcorn) }\end{array}$ \\
\hline
\end{tabular}


of juice and vacuum bags reflect a perception that the two products are easy to manufacture (juice: $M=2.68$; vacuum bags: $M=2.93 ; t(84)=-0.82$, n.s.). Participants also rated their familiarity with the product categories (e.g., "How much do you know about vacuums?"). Familiarity did not significantly vary between the product categories (paired $t$ $(81)=1.10$, n.s.), and it was not a significant covariate in any of the analyses.

\section{Results and discussion}

We analyzed quality ratings for the second product with a $2 \times 2$ analysis of variance (ANOVA). As predicted, the manufacturing difficulty of the first product that consumers learned about influenced quality inferences. There were significant main effects for product benefit similarity and manufacturing difficulty information $(F(1,82)=24.95$, $p<.05 ; F(1,82)=15.43, p<.05)$. The interaction between difficulty and similarity was not significant $(F(1,82)=2.61$, n.s.), suggesting that the same effect of relative manufacturing difficulty occurs regardless of the particular product pair. As expected, consumers inferred higher quality when both products in the portfolio offered similar benefits than when they offered dissimilar benefits (similar products: $M=6.74$; dissimilar products: $M=4.93$ ). Consistent with Hypothesis 1, consumers inferred higher quality when the initial product was relatively difficult to manufacture than when it was relatively easy to manufacture (difficult initial product: $M=6.54$; easy initial product: $M=5.13$ ). Because consumers saw the same products paired in different conditions, in which one was always more difficult than the other, these results suggest that the relative difficulty of manufacture influences quality inferences. However, it is possible that the effects emerged because of more negative attitudes toward firms that make easy products than toward firms that make difficult products. Positive evaluations of similarly easy products would rule out this explanation. We addressed this issue in Study 2 by examining situations in which products are similar rather than discrepant in manufacturing difficulty.

In summary, the impression created by knowledge about one of the firm's products constrains and shapes quality expectations. Overall, the results support our hypothesis about the proposed effects of relative manufacturing difficulty on impressions of a firm's ability to make a high-quality product. That is, information that a firm makes a high-quality product appears to create an impression of the firm's ability to make other high-quality products, based on the relative difficulty of manufacturing the products. Consumers expressed skepticism about the second product's quality when it was relatively more difficult to manufacture (see Table 1). Even when products offered similar benefits, impressions based on the more difficult product led to significantly more positive quality perceptions than impressions based on the relatively easy product ( $M=7.15$ vs. $M=6.32$, respectively; $t(44)=2.04$, $p<.05$ ). The absence of an interaction between benefit similarity and manufacturing difficulty suggests that manufacturing difficulty provides evidence of generalized manufacturing competence that appears to shore up consumers' confidence in the firm's ability, beyond that of having expertise in a particular domain.

\section{Study 2}

Study 2 used one of the same product pairs as in the previous studies but manipulated perceived manufacturing difficulty to test Hypotheses 1 and 2. Prior research has varied difficulty of manufacture by pairing unique combinations of products (e.g., beer extended to popcorn, but not the reverse). To avoid potential confounds inherent in such a method, Study 2 manipulated manufacturing difficulty directly, while using the same product pairing in all conditions (i.e., juice was the initial product, followed by vacuums in all conditions). Information about manufacturing difficulty varied, but the type of product did not.

\section{Method}

Ninety-one students ( $45 \%$ were female and $55 \%$ were male, with a mean age of 20.6 years) completed a questionnaire in exchange for partial course credit in an undergraduate introductory marketing course. A $2 \times 2$ full-factorial betweensubjects design was used, varying the perceived difficulty of manufacturing the initial product of the company (easy vs. difficult to manufacture) and the relative difficulty of manufacturing the two products (similar in manufacturing difficulty vs. discrepant in manufacturing difficulty). We manipulated perceptions of the difficulty of manufacturing the two products using the same products across conditions. The initial product introduced to participants was always juice, and the second product introduced was vacuum cleaners. We manipulated perceptions of difficulty by describing the manufacturing process as either simple or complex (see Table 1).

In all conditions, participants were first told that a consumer magazine had ranked the beverages from many different companies on the basis of their quality and that the juice from a particular company was among the top-ranked brands. Participants were given a brief description of the process of making the juice, which was described as "a carbonated juice made from white grapes." In the conditions in which the juice was described as easy to manufacture, participants were told that the quality of the juice depended primarily "on a simple process of sorting out the ripe grapes from rotten grapes." In contrast, in the 
conditions in which the juice was described as difficult to manufacture, participants were told that the process of making the juice was complex because the quality of the juice depends "on a very precise combination of ingredients and on very careful control of the carbonation process while the juice is being prepared." After this manipulated description, participants rated the perceived quality of the company's juice.

After all participants rated the quality of the company's juice, they were told that the company also makes vacuum cleaners. When both products were similarly easy to manufacture, participants were told that the quality of vacuums depends mainly on "assembling a simple motor and placing it in a prefabricated body." When both products were similarly difficult to manufacture, participants were told that the quality of the vacuums depends on "the design of the product as well as on the precision of the manufacturing and assembly of the parts." When difficulty was discrepant for the two products and the juice was difficult, the vacuum was described as easy to manufacture (i.e., the juice involved a complex manufacturing process, but manufacturing the vacuums involved only simple assembly). When the products' difficulty was discrepant for the two products and the juice was easy, the vacuum was described as difficult to manufacture (i.e., the juice quality depended on a simple process, but vacuum quality required precision in manufacturing and assembly).

After participants read about the company's juice, they were asked to rate the quality of that initial product as a manipulation check, using the same measure as in Study 1. The three items showed high reliability in measuring perceived quality $(\alpha=.98)$. As intended, the mean rating indicated that respondents believed that the juice was high in quality $(M=8.06)$. Perceptions of the quality of the juice did not vary significantly by condition $(F(3,87)=1.44$, n.s.). After participants read the manipulated description of the difficulty of manufacturing vacuums, they were asked to rate the quality of the company's vacuum cleaners using the same three items $(\alpha=.95)$.

After participants rated the quality of the initial and second product, they rated the perceived difficulty of manufacturing the two products. When juice was described as difficult to manufacture, participants perceived it as significantly more difficult than when it was described as easy to manufacture $(M=5.87$ vs. $M=4.17$, respectively; $t(89)=4.69, p<.05)$. When vacuum cleaners were described as easy to manufacture, participants perceived them as significantly less difficult than when they were described as difficult to manufacture $(M=4.67$ vs. $M=5.88$, respectively; $t(89)=-3.01, p<.05)$.

In addition, the manipulation of the similarity of manufacturing difficulty within each condition was successful. In the discrepant-difficulty conditions, participants perceived the initial product as easier than the second product when the initial product was described as easy to manufacture (initial product: $M=4.19$; second product: $M=$ $5.81 ; t(20)=-3.34, p<.05)$. Participants perceived the initial product as more difficult than the second product when the initial product was described as difficult to manufacture (initial product: $M=6.08$; second product: $M=4.50 ; t(23)=$ $2.06, p<.05)$. In the similar-difficulty conditions, participants perceived the two products as similarly difficult when the initial product was difficult to manufacture (initial product: $M=5.62$; second product: $M=5.95 ; t(20)=-0.62$, n.s.). When the initial product was easy to manufacture and the second product was intended to be similarly easy, participants perceived the two products as similarly easy to manufacture (initial product: $M=4.16$; second product: $M=$ $4.84 ; t(24)=-1.87, p>.05)$.

Results and discussion

We analyzed quality ratings for the second product with a $2 \times 2$ ANOVA. There was one significant main effect: the perceived difficulty of manufacturing the initial product (juice) significantly influenced perceptions of the quality of the second product (vacuum cleaners) $(F(1,87)=12.26$, $p<.05$ ). This main effect is qualified by a significant interaction between the initial product's relative manufacturing difficulty and the products' discrepancy in manufacturing difficulty $(F(1,87)=28.98, p<.05)$. The interaction provides evidence of the effect predicted in Hypothesis 1 about quality ratings when the products in the firm's portfolio were discrepant in manufacturing difficulty. Quality ratings for vacuums were the most negative when juice was perceived as easy to manufacture, but vacuums were perceived as difficult to manufacture $(M=4.13$; see Table 1$)$. They were the most positive when juice was perceived as difficult to manufacture but vacuums were perceived as easy to manufacture $(M=7.22 ; t(43)=-7.85, p<.05)$.

Hypothesis 2 focuses on comparisons between quality ratings when products are similar in manufacturing difficulty compared to quality ratings of products that are discrepant in manufacturing difficulty (e.g., an easy initial product but a difficult second product). In support of Hypothesis 2, when the initial product was considered easier than the second, quality ratings of the second product were more negative than when both products were considered similar in manufacturing difficulty (similarly easy: $t(44)=-5.08, p<.05$; similarly difficult: $t(40)=-2.58$, $p<.05)$. Thus, easy initial products by themselves do not elicit negative evaluations. Indeed, when both products were similar in perceived difficulty, the manufacturing difficulty of the initial product had no effect on quality ratings. Regardless of whether the two products were perceived as similarly easy or similarly difficult to manufacture, ratings of the quality of vacuums did not 
significantly differ $(M=6.31$ vs. $M=5.65$, respectively; $t(44)=$ 1.15 , n.s.).

These results support our main contention that the relative manufacturing difficulty of products in a firm's portfolio influences quality perceptions (Hypotheses 1 and 2 ). The lowest quality ratings occurred when the initial product was perceived as easier to manufacture than the second product. The highest quality ratings emerged when the initial product was perceived as more difficult to manufacture than the second product, followed by ratings when both products were similarly difficult to manufacture. Consistent with Hypothesis 1, when the initial product was perceived as more difficult than the second product, quality ratings of the second product were more positive than when both products were perceived as similarly difficult $(t(47)=2.29, p<.05)$. This pattern is inconsistent with the notion that positive attitudes toward a high-quality product transfer to another product that is considered similar in difficulty more than to a product that is considered discrepant in difficulty. Rather than suggesting a mere transfer of affect across similar products, our results suggest a more complex process that involves inferences based on manufacturing difficulty.

Overall, the results of Studies 1 and 2 suggest that consumers use their impressions of a firm's manufacturing ability to estimate another product's quality. We designed Study 3 to extend the generalizability of our findings to real brands and to clarify the relationship between manufacturing difficulty effects and beliefs about the firm's manufacturing ability.

\section{Study 3}

The main purpose of Study 3 was to test Hypothesis 3, which predicts that direct information about the manufacturing ability of the firm will negate the effects of relative manufacturing difficulty. Direct information about a firm's manufacturing ability should eliminate consumers' need to infer ability from the relative manufacturing difficulty of the products. Thus, the relative manufacturing difficulty of the products should no longer influence respondents' product-quality ratings. The remaining Study 3 respondents lacked direct information about a firm's manufacturing ability, similar to respondents in Studies 1 and 2. Therefore, these respondents should show the same pattern of quality perceptions as respondents in Studies 1 and 2, consistent with Hypothesis 1.

Study 3 also differed from Studies 1 and 2 by using real brand names and a different set of products. We chose Heineken and Orville Redenbacher as the brands to study because Aaker and Keller (1990) used the pairing of Heineken beer and popcorn in their study. In addition, these two brands are each associated with a single product category rather than with multiple products.

\section{Method}

One hundred students completed a questionnaire in exchange for partial course credit in an undergraduate introductory marketing course (54\% were female and $46 \%$ were male, with a mean age of 21.0 years). A $2 \times 2$ full-factorial between-subjects design was used. One factor varied manufacturing difficulty of the initial product (relatively difficult vs. relatively easy), and the other factor varied the information provided about the company's manufacturing ability (high-ability vs. no-ability information).

When we used Heineken beer as the initial difficult-tomanufacture branded product, the second product for which quality inferences were to be made was a Heineken extension into popcorn. To maintain the same product categories, the initial easy-to-manufacture branded product was Orville Redenbacher's popcorn with the extension into beer. To rule out prestige as an alternative explanation for our findings (Park et al. 1991), participants rated the extent to which the products are perceived as prestigious. However, image prestige was not a significant covariate in the analysis of any of the dependent variables, and thus we do not discuss it further.

The manufacturing ability manipulation consisted of providing half of the participants with high-ability information about the company associated with the brand. In the high-ability conditions, participants were told that an investment firm had ranked companies that produce consumer goods in terms of their ability to manufacture high-quality products. Thus, respondents were given information about the firm's general manufacturing ability, without reference to their ability to manufacture any specific product. Although most consumers are unlikely to have such information, our manipulation is similar to previous research manipulating corporate ability and thus serves our theory testing purposes. For example, to manipulate perceptions of a firm's ability, Brown and Dacin (1997) presented information about the number of a firm's patents. Participants in our study were told, "Heineken (Orville Redenbacher) was rated as one of the top manufacturers, with a very high level of manufacturing ability and knowledge about production and quality control." In the no-ability-information control conditions, participants were not provided with investment firm rankings and were given only quality information about the branded product, similar to Studies 1 and 2. Specifically, all participants were told that the brand of beer (popcorn) was rated as one of the top brands on the basis of consumers' ratings of the product's flavor. 
The questionnaire used in this study was similar to those used in Studies 1 and 2. Participants first were asked to rate the quality of the initial product and then were presented with information about the second product and asked to rate that product's quality. The same three-item quality measures as in the first two studies were used, and they exhibited high reliability for both the initial and the second products $(\alpha>.95)$.

We added five items to measure the company's manufacturing ability, preexisting attitudes toward the company, and product familiarity. Participants indicated their perceptions of the company's ability on a single 9-point scale that assessed whether "Heineken (Orville Redenbacher) has a high level of manufacturing ability," from 1 (not at all) to 9 (definitely). We measured attitudes toward the brand by asking participants to rate how they felt about the brand before they completed the survey on 9-point semantic differential scales: negative/positive, unfavorable/favorable, and dislike/like $(\alpha=.97)$. Reported preexisting attitudes toward Orville Redenbacher were not significantly different from attitudes toward Heineken ( $M=6.30$ vs. $M=6.34$; $t(98)=-0.12$, n.s.) and were similarly positive. The same items used in Study 2 examined the perceived benefit similarity of beer and popcorn and the perceived difficulty of manufacturing the products. Participants perceived beer and popcorn as somewhat similar in terms of benefits $(M=$ 4.98), and ratings of benefit similarity did not differ across conditions $(F(3,96)=1.61$, n.s. $)$. As expected, participants perceived beer as significantly more difficult to manufacture $(M=6.79)$ than popcorn $(M=4.98 ; t(99)=19.65$, $p<.05)$. All participants indicated their familiarity with both product categories. Although participants reported being directionally more familiar with beer than with popcorn (paired $t(99)=1.82, p<.10$ ), the means were near the midpoint of the scale (beer: $M=5.06$; popcorn: $M=4.63$, from 1 [not at all familiar] to 9 [very familiar]) and did not vary significantly between conditions $(F(3,96)=0.23$ and 0.61 , respectively, n.s.).

\section{Results and discussion}

The results support Hypothesis 3 and provide additional support for Hypothesis 1 . The manufacturing difficulty of the initial product in a firm's portfolio seems to create an impression of the firm's ability to make another high-quality product. When direct information about a company's manufacturing ability is provided, the effect of relative manufacturing difficulty disappears, suggesting that inferences of ability are responsible for the effects of relative manufacturing difficulty.

Perceptions of the firm's ability Providing high-ability information about the company influenced perceptions of the company's manufacturing ability. The main effect of the ability manipulation on ratings of the company's manufacturing ability indicated that the manipulation was successful. Ratings of manufacturing ability were significantly higher in the high-ability conditions $(M=7.31)$ than in the control conditions $(M=6.71 ; F(1,96)=5.10, p<.05)$. The difficulty of the initial product also significantly influenced ratings of the company's manufacturing ability $(F(1,96)=9.06, p<.05)$; the more difficult initial product led to more positive perceptions of the company's ability than did the easy-to-manufacture product ( $M=7.40$ vs. $M=$ 6.62 , respectively).

Comparison of the ratings of the company's ability in the absence of direct information about the company's ability indicates that manufacturing difficulty indeed serves as a cue to the company's manufacturing ability. When no information about the company's ability was given, the initial product enhanced the first impression of the company's ability more when it was difficult to manufacture than when it was easy to manufacture ( $M=7.32$ vs. $M=$ 6.12 , respectively; $t(49)=3.32, p<.05$ ). Regression analyses also suggest that manufacturing difficulty serves as a cue about the company's ability. In the control conditions, the manufacturing difficulty of the initial product was a significant predictor of participants' perceptions of the company's manufacturing ability $(\beta=0.47, p<.05)$. However, in the conditions in which high manufacturing ability information was provided, initial product manufacturing difficulty did not significantly predict ratings of the company's ability $(\beta=0.21$, n.s.; $t(47)=-0.96$, n.s.). Thus, when high-ability information was provided, participants no longer needed to rely solely on the manufacturing difficulty of the initial product to form impressions of the company's manufacturing ability.

Quality perceptions of the second product We analyzed the data for the main dependent variable in the study using a $2 \times 2$ ANOVA. Importantly, the second product's quality ratings replicated the corresponding findings from Studies 1 and 2, even though different products and brand names were provided to respondents.

There were significant main effects for initial product manufacturing difficulty and for information about the firm's ability, which were qualified by a significant interaction $(F(1,96)=9.16, p<.05 ; F(1,96)=12.49$, $p<.05 ; F(1,96)=10.56, p<.05)$. The interaction effect of initial product difficulty and the manipulation of perceived manufacturing ability on quality perceptions provide support for Hypotheses 1 and 3. Hypothesis 1 predicts that a relatively easier-to-manufacture initial product will lead to more negative perceptions of a second product than a relatively more difficult-to-manufacture initial product. Ratings of the second product's quality were most negative 
when the initial product was relatively easy to manufacture (popcorn) and no ability information was given for the company (i.e., Orville Redenbacher's beer, $M=3.95$; see Table 1). When the initial product was more difficult to manufacture (beer), the easier extension (Heineken popcorn) was given significantly higher quality ratings $(M=6.01 ; t(49)=$ 4.67, $p<.05)$.

Hypothesis 3 suggests that direct information about the firm's high ability enhances consumers' predictions about the quality of other products in the firm's portfolio, even when the initial product is easier to manufacture than the second product. Hypothesis 3 is supported by the mean ratings of the extension's quality when participants were told that the company had high manufacturing ability. When the initial product was easier to manufacture, the mean ratings for the second product's quality were significantly more positive in the high-ability manipulation condition than in the no-ability-information control condition $(M=6.18$ vs. $M=3.95$, respectively; $t(48)=5.42$, $p<.05$ ). The information about the company's manufacturing ability seems to have provided an alternative cue that contradicted and overwhelmed the implications of a relatively easy-to-manufacture initial product. In addition, the extension's quality ratings when the initial product was difficult to manufacture did not differ significantly, depending on the presence or absence of information about the firm's high ability ( $M=6.01$ vs. $M=6.11 ; t(48)=-0.18$, n.s.). Thus, a relatively difficult-to-manufacture initial product seemed to be a sufficient signal of the firm's high manufacturing ability.

We conducted mediation analyses to provide additional evidence that perceptions of manufacturing ability influenced inferences about the quality of the extension based on information about the initial product. Ratings of the company's manufacturing ability mediated the relationship between the extension's quality ratings and initial productquality ratings. When initial product-quality ratings are entered as the sole predictor, they are significantly related to extension product-quality ratings $(\beta=0.24, p<.05)$. However, when variation accounted for by ratings of manufacturing ability is controlled, initial product quality no longer significantly predicts the extension's quality ( $\beta=0.06$, n.s.). Manufacturing ability perceptions are a significant predictor of the extension's quality $(\beta=0.41, p<.05)$, and they fully mediate the relationship between the extension's quality and initial product quality (Baron and Kenny 1986). This result provides further evidence that perceptions of manufacturing ability influence quality perceptions for the second product. Nevertheless, direct information about a firm's manufacturing ability, such as the information we provided to respondents, is rarely available. In the absence of direct information, consumers appear to make inferences about a firm's ability from the products they manufacture.
Summary Study 3 results replicate the support for Hypothesis 1 found in Studies 1 and 2. All three studies find consistent effects using a method of systematically varying relative manufacturing difficulty. A review of eight brand extension studies found inconsistent effects for manufacturing difficulty on attitudes toward an extension (Bottomley and Holden 2001). Those studies examined the difficulty of the extension but not of the parent. Our findings suggest a reason for the inconsistent findings across studies; manufacturing difficulty influences consumers' quality perceptions in more complex ways than can be assessed by taking into account only the extension product's manufacturing difficulty. For example, Study 2 suggests different consumer reactions to a difficult-to-manufacture extension when the parent product is similarly difficult rather than when it is relatively easy to manufacture. In sum, perceptions of a product's manufacturing difficulty may have greater effects on product quality inferences than Bottomley and Holden's (2001) review suggests.

\section{General discussion}

This research focuses on inferences about the firm's ability to make high-quality products based on the relative manufacturing difficulty of the original and extension products. The three experiments show that relative differences in perceived manufacturing difficulty of products in the portfolio influence product-quality inferences. The results reported herein clarify the conditions under which impressions of the firm's ability have the greatest effect on quality expectations. Discrepancies in the perceived difficulty of manufacturing two products can hurt the firm when the consumer's impression is based on an easy-to-manufacture product. Thus, findings that seem to be unique to the brand extension literature may be subsumed within more general principles about consumers' inferences about a firm's portfolio. Expectations of quality can be asymmetrical for the same two products, depending on which one the consumer learns about first, regardless of whether, from the firm's perspective, the product is the parent or the extension.

Consumers are likely to use manufacturing difficulty to make quality inferences because it is often accessible, concrete, and easy to process. These features increase the likelihood that a cue will be used (Hansen and Zinkhan 1984). Nevertheless, other cues can provide stronger signals of quality. Because our purpose was to clarify previous inconsistent findings by controlling potentially confounding variables, our stimulus materials limited accessibility to other potential quality cues. Perhaps providing respondents with limited information made manufacturing difficulty a more salient cue than it would 
be in a more natural environment. Previous research has used multicue studies and suggested that manufacturing difficulty can sometimes have a significant effect when other cues are present (Bottomley and Holden 2001). Nevertheless, other quality cues (e.g., price) are similarly compelling (Hansen and Zinkhan 1984). Future research should further examine manufacturing difficulty in the context of other quality cues.

Future research should also investigate whether our results generalize to other populations and to other product pairs. All three experiments used student respondents. It may be that students' naive theories about the difficulty of manufacturing products and the relationship between difficulty and ability are idiosyncratic and that other populations would have different theories about the relationship. Nevertheless, the relationship between task difficulty and ability in judgments in the context of individual achievement suggests the pervasiveness of this belief (e.g., Meyer et al. 1976), which gives us confidence that the results are generalizable.

Furthermore, even consumers who are familiar with a product through extended use may rely on the same simple assessments of the difficulty of manufacturing the product as those who merely know the product's function, because neither population is likely to have much insight into manufacturing processes. However, consumers' naïve theories may be quite different from managers' knowledge about and inferences based on the difficulty of manufacturing various products. Finally, it is possible that some unique characteristics of the product pairs we used influenced the results (e.g., differences in perceived typicality for the product class, differences in product familiarity).

This research suggests that consumers' perceptions of the difficulty of manufacturing a product can influence their evaluations of another product from the same firm. These findings imply that companies must be careful in planning and implementing strategy to form an impression with consumers that will allow for growth and maximization of the company's capabilities. Companies may be able to strategize whether they want consumers to know about all the products they make and, if they do, about the order in which to expose consumers to products in their portfolio.

Industries that rely on business-to-business communications and firms that can implement more targeted marketing communications may have the greatest control over which products their customers learn about first. Industries in which mass marketing and wide distribution is the norm may often have little control over the product that creates consumers' first impression of the firm's ability. However, there are situations in which companies could use manufacturing difficulty to create a positive first impression. For example, a new company could be strategic about product introduction. Companies that expand to new markets could use manufacturing difficulty to shape consumers' product quality perceptions.

This research can also be applied to branding strategy. For example, a company that consumers know manufactures relatively simple products might be well advised to create a new brand when introducing a more complex product. Conversely, this research implies that a brand associated with complex, difficult-to-manufacture products should have greater extendibility into products that are perceived as relatively simple.

Acknowledgements The authors appreciate the helpful comments of David Stewart and C. W. Park on a previous draft of this paper, and the insights of George Zinkhan and three anonymous reviewers.

\section{References}

Aaker, D. A., \& Keller, K. (1990). Consumer evaluations of brand extensions. Journal of Marketing, 54, 27-41, January.

Baron, R. M., \& Kenny, D. A. (1986). The moderator-mediator variable distinction in social psychological research: Conceptual, strategic, and statistical considerations. Journal of Personality and Social Psychology, 51, 1173-1182, June.

Bottomley, P. A., \& Holden, S. J. S. (2001). Do we really know how consumers evaluate brand extensions? Empirical generalizations based on secondary analysis of eight studies. Journal of Marketing Research, 38, 494-500, November.

Boush, D. M., \& Loken, B. (1991). A process-tracing study of brand extension evaluation. Journal of Marketing Research, 28, 16-28, February.

Brown, T. J., \& Dacin, P. (1997). The company and the product: Corporate associations and consumer product responses. Journal of Marketing, 61, 68-84, January.

Hansen, C. J., \& Zinkhan, G. M. (1984). When do consumers infer product attribute values? In Advances in consumer research (Vol. 11, pp. 187-192). Provo, UT: Association for Consumer Research.

Hogarth, R., \& Einhorn, H. (1992). Order effects in belief updating: The belief-adjustment model. Cognitive Psychology, 24(1), 1-55.

Jones, E., Rock, L., Shaver, K., Goethals, G., \& Ward, L. (1968). Pattern of performance and ability attribution: An unexpected primacy effect. Journal of Personality and Social Psychology, 4, 247-269, April.

Kirmani, A., \& Rao, A. R. (2000). No pain, no gain: A critical review of the literature on signaling unobservable product quality. Journal of Marketing, 64, 66-79, April.

Martin, I. M., \& Stewart, D. W. (2001). The differential impact of goal congruency on attitudes, intentions, and the transfer of brand equity. Journal of Marketing Research, 38, 471-484, November.

Meyer, W.-U., Folkes, V. S., \& Weiner, B. (1976). The perceived information value and affective consequences of choice behavior and intermediate difficulty task selection. Journal of Research in Personality, 10, 410-423, December.

Park, C. W., Milberg, S. L., \& Lawson, R. (1991). Evaluation of brand extensions: The role of product feature similarity and brand concept consistency. Journal of Consumer Research, 18, 185-193, September.

Weiner, B., \& Kukla, A. (1970). An attributional analysis of achievement motivation. Journal of Personality and Social Psychology, 15, 1-20, January.

Zeithaml, V. (1988). Consumer perceptions of price, quality, and value: A means-end model and synthesis of evidence. Journal of Marketing, 52, 2-22, July. 